\title{
НАРУШЕНИЯ ГОМЕОСТАЗА ПРИ ХРОНИЧЕСКОЙ ОБСТРУКТИВНОЙ БОЛЕЗНИ ЛЕГКИХ
}

\author{
() Ахминеева А.Х., Полунина О.С., Севостьянова И.В. \\ Кафедра внутренних болезней педиатрического факультета \\ Астраханского государственного медицинского университета, Астрахань \\ E-mail: irina-nurzhanova@yandex.ru
}

\begin{abstract}
В работе были изучены показатели функционального состояния сосудистого эндотелия (коэффициент эндотелиальной функции, уровни эндотелина-1 и натрийуретического пептида типа С), перекисного окисления белков (карбонильные производные), липидов (ТБК-активные продукты), антиоксидантной защиты (супероксиддисмутаза) и воспаления (С-реактивный белок и фракталкин) у 35 пациентов с хронической обструктивной болезнью легких (ХОБЛ) и 50 соматически здоровых лиц Астраханского региона. У больных ХОБЛ установлено наличие дисфункции эндотелия и окислительного стресса, опосредованного перекисной деструкцией как липидных, так и белковых молекул. Констатирована прямая корреляционная зависимость между уровнем плазменного эндотелина-1 и уровнем ТБК-активных продуктов, отражающая увеличение продукции вазоконстрикторов при увеличении уровня продуктов перекисного окисления липидов у больных ХОБЛ. Было доказано, что исследование 4a/4b полиморфизма гена eNOS имеет важное значение в диагностике повреждения эндотелия при ХОБЛ.
\end{abstract}

Ключевые слова: хроническая обструктивная болезнь легких, гомеостаз, эндотелиальная дисфункция, оксидативный стресс, воспаление, полиморфизм генов.

\section{HOMEOSTATIC DISORDERS IN CHRONIC OBSTRUCTIVE PULMONARY DISEASE Akhmineeva A.Kh., Polunina O.S., Sevostyanova I.V.}

\section{Department of Internal Diseases of Pediatric Faculty of Astrakhan State Medical University, Astrakhan}

The research studied the parameters of the vascular endothelium functional state (the ratio of endothelial function, levels of endothelin-1 and natriuretic peptide of type C) of peroxide oxidation of proteins (carbonyl derivatives), of lipids (TBAactive products), of antioxidant protection (superoxide dismutase) and inflammation ( $\mathrm{C}$ - reactive protein and fractalkine) in 35 patients with chronic obstructive pulmonary disease (COPD) and 50 somatically healthy persons of Astrakhan region. It was revealed that COPD patients had endothelial dysfunction and oxidative stress due to the peroxide destruction of both lipid and protein molecules. We stated a direct correlation between the level of plasma endothelin-1 and the level of TBA-active products reflecting an increase in production of vasoconstrictors with increasing levels of lipid peroxidation products in patients with COPD. It has been proven that the study of $4 \mathrm{a} / 4 \mathrm{~b}$ polymorphism of the eNOS gene is important in the diagnosis of endothelial damage in COPD.

Keywords: chronic obstructive pulmonary disease, homeostasis, endothelial dysfunction, oxidative stress, inflammation, gene polymorphism.

Хроническая обструктивная болезнь легких (ХОБЛ) - распространенное заболевание системы дыхания у человека, являющееся одной из основных причин нетрудоспособности, инвалидности, значительно снижающее качество жизни пациентов и занимающее четвертое место среди причин смерти в промышленно развитых странах $[1,9]$.

Одну из ключевых ролей в молекулярных механизмах патогенеза ХОБЛ играет оксидативный стресс $[3,5]$. Оксидативный стресс при ХОБЛ носит не только местный, но и системный характер. Это ведет к тому, что поражаются не только дыхательные пути, но системная циркуляция, а это в свою очередь может приводить к повреждению эндотелия и развитию атеросклероза [10, 11]. Разработка современных достоверных методов, позволяющих прогнозировать особенности течения ХОБЛ, является одной из актуальных задач пульмонологии. Перспективными в этом плане считаются исследования, посвященные изучению вклада генетических маркеров в развитие и прогрессирование ХОБЛ [8].

Целью исследования стало изучение показателей эндотелиальной функции, оксидативного стресса и активности воспаления при хронической обструктивной болезни легких.

\section{МАТЕРИАЛЫ И МЕТОДЫ ИССЛЕДОВАНИЯ}

Работа выполнена в рамках реализации гранта Президента РФ по государственной поддержке молодых ученых-кандидатов наук за проект «Эндотелиальная дисфункция и оксидативный стресс в развитии респираторно-кардиальной коморбидности» (МК-5572.2013.7). Проведение данного клинического исследования одобрено Региональным независимым этическим 
комитетом (заседание РНЭК от 17.09.2012, протокол № 2).

Исходя из цели исследования, было обследовано 35 пациентов с обострением ХОБЛ и 50 лиц соматически здоровых лиц Астраханского региона. Все пациенты были сопоставимы по ряду социально-демографических показателей. Критериями включения в исследование были ХОБЛ средней и тяжелой степени тяжести. Диагноз ХОБЛ и стадии заболевания устанавливались по рекомендациям, представленным программой «Глобальная стратегия диагностики, лечения и профилактики хронической обструктивной болезни легких» [1].

Средний возраст обследованных больных составил 62,9 [48; 72] года. Средняя длительность заболевания - 17,5 [3; 24] года.

Доля курящих лиц на период обследования составила $87,8 \%$. Анамнез курения у $100 \%$. Средний индекс курения составил 32,6 [12; 48] пачка-лет.

Исследование функционального состояния кожных микрососудов осуществлялось методом лазерной допплеровской флоуметрии (ЛДФ) с помощью лазерного анализатора тканевого кровотока «ЛАКК-02» в одноканальной модификации («Лазма», г. Москва). Для оценки сосудодвигательной функции эндотелия в ходе ЛДФ проводились ионофоретические пробы с 5\% раствором ацетилхолина и с $5 \%$ раствором нитропруссида натрия и вычислялся коэффициент эндотелиальной функции (КЭФ), как отношение степени прироста показателя микроциркуляции при ионофорезе ацетилхолина к степени увеличения показателя микроциркуляции при ионофорезе нитропруссида натрия [7]. На основании данных ионофоретической пробы с $5 \%$ раствором ацетилхолина (эндотелий-зависимого вазодилататора) у каждого пациента нами делалось заключение о типе реагирования микрососудистого эндотелия. Для определения одного из девяти возможных типов реагирования эндотелия на ионофорез ацетилхолина мы использовали классификацию, предложенную Л.П. Ворониной с соавторами [6].

Исследование металл-катализируемой окислительной модификации белков в сыворотке крови проводилось по методу R.L. Levine в модификации Е.Е. Дубининой (1995) посредством определения уровня карбонильных производных (КП) в сыворотке крови спектрофотометрическим методом с использованием 2,4-динитрофенилгидразина [2]. Для количественного определения содержания ТБК-активных продуктов и карбонильных производных в сыворотке крови использовали диагностические наборы «ТБКАГАТ» фирмы «Биоконт», г. Москва, РФ.
Определение активности супероксиддисмутазы (СОД) в сыворотке крови производилось с использованием коммерческих диагностических наборов «SOD kit» фирмы «Randox Laboratories LTD», United Kingdom.

Изучение уровня натрийуретического пептида типа С (НУПС) в образцах плазмы осуществлялось методом иммуноферментного анализа с помощью коммерческой тест системы «NTproCNP» (каталожный номер BI-20872, фирма «Biomedica Medizinprodukte GmbH\&Co KG», Австрия). Исследование уровня эндотелина-1 в образцах плазмы осуществлялось с помощью иммуноферментного набора для количественного определения эндотелина (1-21) в биологических жидкостях фирмы «Biomedica», Германия.

Определение С-реактивного протеина (СРП) проводили методом иммунотурбодиметрии с латексным усилением. Минимально определяемая концентрация СРП составила 0,1 мкг/мл. Для калибровки использовали коммерческий мультикалибратор «CRP (HS) Wide Range Multi Calibrator Set HTI» фирмы «High Technology Inc.», США.

Определение уровня фракталкина в образцах плазмы осуществлялось с помощью иммуноферментного набора для количественного определения фракталкина (CX3CL1) в биологических жидкостях с применением тест-системы «RayBio ${ }^{\circledR}$ Human Fractalkine», фирмы «RayBiotech, Inc.», США.

Генотипирование по полиморфному маркеру гена эндотелиальной синтазы оксида азота (eNOS) проводили на геномной ДНК, выделенной из цельной крови. В качестве контроля полиморфизм указанного гена был исследован у 50 соматически здоровых лиц. Полиморфные участки гена eNOS амплифицировали с помощью полимеразной цепной реакции, используя структуру праймеров и параметры температурных циклов, описанных в геномной базе данных.

Статистическая обработка данных проводилась с помощью программы STATISTICA 12.0, Stat Soft, Inc [4]. Для каждого показателя и групп наблюдений вычисляли медиану, верхний и нижний квартили. Объективную проверку на нормальность распределения проводили с помощью теста Колмогорова-Смирнова с коррекцией значимости по Лиллифору. Поскольку в большинстве групп признаки имели отличное от нормального распределение, то для проверки статистических гипотез при сравнении числовых данных двух несвязанных групп использовали Mann-Whitney test, при сравнении трех несвязанных групп использовали KruskalWallis ANOVA test. Оценка интенсивности корреляционной связи проводилась с помощью 
рангового коэффициента корреляции Спирмена. Критический уровень статистической значимости принимали 5\% $(\mathrm{p}=0.05)$.

\section{РЕЗУЛЬТАТЫ ИССЛЕДОВАНИЯ И ИХ ОБСУЖДЕНИЕ}

Нами была предпринята попытка оценить функциональное состояние сосудистого эндотелия у больных ХОБЛ методом лазерной допплеровской флоуметрии (ЛДФ). В зависимости от значения КЭФ, нами выделялись пациенты с нормальным функциональным состоянием сосудистого эндотелия, имевшие значение КЭФ 1 и более, пациенты с умеренной дисфункцией сосудистого эндотелия (КЭФ<1, но $\geq 0.8)$ и пациенты с выраженной дисфункцией сосудистого эндотелия (КЭФ <0.8).

Значение КЭФ в группе больных ХОБЛ составило 0.89 ед. (т.е. было меньше 1), что указывало на нарушение функционального состояния микрососудистого эндотелия и развитие эндотелиальной дисфункции (ЭД). Причем ЭД развивалась более чем у 95\% больных ХОБЛ, так как значение 95 процентиля КЭФ равное 0.95 ед., было также меньше 1. При сравнении значения медианы КЭФ, в группе больных ХОБЛ с группой соматически здоровых лиц обращает на себя внимание статистически значимое $(p=0.00001)$ снижение данного показателя в группе больных ХОБЛ - 0.89 ед. против 1.53 ед. Кроме того, в группе больных ХОБЛ интерквартильные $[0.77 ; 0.95]$ и интерпроцентильные $[0.72 ; 1.18]$ размахи КЭФ были визуально ниже, чем в группе соматически здоровых лиц $-[1.25 ; 1.72]$ и $[1.14 ; 1.89]$ соответственно, что также отражало развитие ЭД у больных ХОБЛ. При проведении сравнительного анализа состояния сосудистого эндотелия было выявлено статистически значимое $(\mathrm{p}=0.001088)$ снижение КЭФ и, следовательно, ухудшение вазодилатирующей способности эндотелия у пациентов с ХОБЛ по сравнению с группой соматически здоровых лиц. При анализе частоты встречаемости ЭД различной выраженности в исследуемых группах было установлено, что в группе больных ХОБЛ преобладала умеренная ЭД, встречавшаяся у 54\% обследованных, что было статистически значимо $\left(\chi^{2}=6.28 ; \mathrm{df}=1\right.$; $\mathrm{p}=0.012)$ чаще по сравнению с количеством пациентов данной группы без ЭД (12\%). Выраженная ЭД была выявлена у 34\% пациентов c ХОБЛ. Различия с частотой встречаемости умеренной ЭД были статистически незначимы $\left(\chi^{2}=1.1 ; \quad \mathrm{df}=1 ; \quad \mathrm{p}=0.294\right) . \quad$ При проведении сравнительного анализа частоты встречаемости ЭД различной выраженности в группах пациен- тов с ХОБЛ было установлено, что среди больных ХОБЛ статистически значимо $\left(\chi^{2}=7.56 ; \mathrm{df}=1\right.$; $\mathrm{p}=0.0060)$ редко встречаются пациенты с сохранным функциональным состоянием сосудистого эндотелия.

Таким образом, при проведении анализа функционального состояния сосудистого эндотелия у пациентов с ХОБЛ, было выявлено развитие эндотелиальной дисфункции (ЭД).

Далее мы предприняли попытку оценить в исследуемых группах особенности реагирования микрососудов на ионофорез эндотелий-зависимого вазодилататора с выделением типов реагирования, выражающихся в различном времени подъема и спада допплерограммы [6].

В группе пациентов с ХОБЛ частота выявления нормореактивно-стабильного типа реагирования микрососудистого эндотелия, характеризующегося сохранной чувствительностью эндотелиальных рецепторов, стабильностью скорости, времени и объема продукции и депонирования вазодилататоров в микрососудистом эндотелии, составила 8\%. Частота выявления нормореактивно-декрементного типа реагирования микрососудистого эндотелия, характеризующегося сохранной чувствительностью эндотелиальных рецепторов и уменьшением продолжительности вазодилатации, составила $46 \%$, что было сопоставимо с частотой выявления гипореактивно-декрементного типа, характеризующегося снижением чувствительности микрососудистых эндотелиальных рецепторов и уменьшением продолжительности вазодилатации микрососудов (46\% пациентов данной группы). Таким образом, для больных ХОБЛ характерна нормальная (54\%) или сниженная (46\%) чувствительность микрососудистых рецепторов в сочетании с уменьшением продолжительности вазодилатации микрососудов (92\% пациентов).

При оценке функционального состояния эндотелия сосудов важное значение имеет определение уровня эндотелина-1, натрийуретического пептида типа С и генетических маркеров поражения эндотелия (полиморфизм гена эндотелиальной синтазы оксида азота). Уровень ЭТ-1 в плазме крови больных ХОБЛ статистически значимо $(\mathrm{p}<0.001)$ превышал уровень ЭТ-1 в плазме соматически здоровых лиц. Так, медиана, интерквартильные и интерпроцентильные $(5 ; 95)$ размахи уровня ЭТ-1 при ХОБЛ составили 6.9 [4.4; 8.1], [3.1; 9.8] пг/мл против 3.3 [3.1; 3.5], [3.0; 3.9] пг/мл в группе соматически здоровых лиц, что отражало гиперпродукцию данного пептида при указанной патологии и развитие дисфункции эндотелия. Уровень натрийуретического пептида типа С (НУПС) у больных ХОБЛ также статистически значимо $(\mathrm{p}<0.001)$ превышал 
уровень НУПС в группе соматически здоровых лиц.

Мы предприняли попытку изучить взаимосвязь между полиморфизмами $4 \mathrm{a} / 4 \mathrm{~b}$ и $4 \mathrm{~b} / 4 \mathrm{~b}$ гена eNOS и уровнем в плазме ЭТ-1 и НУПС, т.е. с ЭД, в изучаемых группах. Частота встречаемости $4 \mathrm{a} / 4 \mathrm{~b}$ генотипа в группе соматически здоровых лиц составила $37 \%$, что было сопоставимо с частотой встречаемости $4 \mathrm{~b} / 4 \mathrm{~b}$ генотипа - 63\% $\left(\chi^{2}=1.22 ; \quad \mathrm{df}=1 ; \mathrm{p}=0.296\right)$. При исследовании частоты встречаемости аллелей $4 \mathrm{a}$ и $4 \mathrm{~b}$ гена eNOS было выявлено статистически значимое преобладание 4b аллеля в группе соматически здоровых лиц $\left(\chi^{2}=14.93 ; \mathrm{df}=1 ; \mathrm{p}<0.001\right)$ и группе больных ХОБЛ $\left(\chi^{2}=19.28 ; \mathrm{df}=1 ; \mathrm{p}<0.001\right)$

Далее мы изучили уровень ЭТ-1 у пациентов исследуемых групп в зависимости от генотипа $(4 \mathrm{a} / 4 \mathrm{~b}$ и 4b/4b) гена эндотелиальной синтазы оксида азота. В обеих группах у лиц с генотипом 4a/4b уровень ЭТ-1 был статистически значимо (Mann-Whitney test) выше по сравнению с пациентами с генотипом 4b/4b, что отражает увеличение продукции ЭТ-1 у лиц с VNTRполиморфизмом. Так, в группе соматически здоровых лиц у пациентов с $4 \mathrm{a} / 4 \mathrm{~b}$ уровень ЭТ-1 составил 3.7 [3.4; 5.9] пг/мл и был статистически значимо $(\mathrm{p}=0.049)$ выше, чем у пациентов с генотипом 4b/4b. В группе больных ХОБЛ у пациентов с генотипом $4 \mathrm{a} / 4 \mathrm{~b}$ уровень ЭТ-1 составил 8.3 [6.8; 10.4] Пг/мл, что было статистически значимо выше по сравнению с пациентами с генотипом 4b/4b $(\mathrm{p}=0.011)$. При сравнении с группой соматически здоровых лиц уровень ЭТ-1 у больных ХОБЛ был статистически значимо выше, как у пациентов с генотипом $4 \mathrm{a} / 4 \mathrm{~b}(\mathrm{p}=0.001)$, так и у пациентов с генотипом $4 \mathrm{~b} / 4 \mathrm{~b}(\mathrm{p}=0.011)$.

Среди больных ХОБЛ у пациентов с генотипом 4a/4b уровень НУПС составил 15.2 [11.1; 18.7] пг/мл, что было статистически значимо выше по сравнению с пациентами с генотипом 4b/4b $(p<0,001)$. При сравнении с группой соматически здоровых лиц уровень НУПС в группе больных ХОБЛ был статистически значимо выше как у пациентов с генотипом $4 \mathrm{a} / 4 \mathrm{~b}(\mathrm{p}<0.001)$, так и у пациентов с генотипом $4 \mathrm{~b} / 4 \mathrm{~b}(\mathrm{p}=0.002)$.

Актуальным, на наш взгляд, было установление роли фракталкина (ФКН) как маркера воспалительной активации и фактора повреждения эндотелия при ХОБЛ. Уровень ФКН в плазме крови больных ХОБЛ статистически значимо $(\mathrm{p}<0,001)$ превышал уровень ФКН в плазме соматически здоровых лиц. Так, медиана, интерквартильные и интерпроцентильные $(5 ; 95)$ размахи уровня ФКН при ХОБЛ составили 1.23 [0.75; 2.01], [0.38; 2.19] нг/мл против 0.31 [0.31;
0.32], [0.30; 0.35] нг/мл в группе соматически здоровых лиц, что отражало гиперпродукцию данного пептида у больных ХОБЛ и наличие системной воспалительной активации. Исследовав уровень СРП в сыворотке крови, мы подтвердили наличие у больных ХОБЛ системной воспалительной активации. Так, мы установили, что уровень СРП в сыворотке крови больных ХОБЛ статистически значимо $(\mathrm{p}<0.001)$ превышал уровень СРП в плазме соматически здоровых лиц: медиана, интерквартильные и интерпроцентильные $(5 ; 95)$ размахи уровня СРП при ХОБЛ составили 8.6 [3.8; 13.2], [1.0; 14.6] мкг/мл против 0.7 [0.4; 0.9], [0.1; 2.1] мкг/мл в группе соматически здоровых лиц.

При проведении корреляционного анализа в группе контроля нами не было выявлено статистически значимых коэффициентов корреляции между маркерами ЭД (КЭФ, НУПС, ЭТ-1) и показателями, отражающими активность воспаления (СРП и ФКН). В группе больных ХОБЛ была выявлена обратная корреляционная взаимосвязь слабой силы между значением КЭФ и уровнем СРП $(\mathrm{r}=-0.323 \mathrm{p}=0.035)$ и обратная корреляционная взаимосвязь средней силы между значением КЭФ и уровнем плазменного ФКН $(\mathrm{r}=-0.562 \mathrm{p}<0.001)$. Обращает на себя внимание большая сила и статистическая значимость корреляционной взаимосвязи между КЭФ и ФКН, указывающая, что при ХОБЛ именно запуск цитокинового каскада с активацией хемотаксиса приводит к нарушению функционального состояния сосудистого эндотелия, в том числе его вазодилатирующей функции. Зависимость выработки вазодилататоров от активации цитокиновхемокинов также подтверждалась наличием прямой корреляционной взаимосвязи средней силы между уровнем НУПС и уровнем ФКН $(\mathrm{r}=0.461 \mathrm{p}=0.001)$. Зависимость между уровнем НУПС и СРП была слабой силы, однако статистически значима $(\mathrm{r}=0.325 \mathrm{p}=0.015)$. Также у больных ХОБЛ были выявлены корреляционные взаимосвязи слабой силы между уровнем плазменного ЭТ-1 и уровнями ФКН и СРП $(\mathrm{r}=0.301 \mathrm{p}=0.035 ; \mathrm{r}=0.303 \mathrm{p}=0.035$ соответственно), отражающие повреждающее действие воспалительных факторов на сосудистый эндотелий, сопровождающееся избыточной выработкой вазоконстрикторов, одним из которых является ЭТ-1.

Оксидативный стресс - важнейшее звено патогенеза и прогрессирования хронической обструктивной болезни легких (ХОБЛ).

Уровень ТБК-активных продуктов при ХОБЛ был статистически значимо выше, чем в группе соматически здоровых лиц. У пациентов с ХОБЛ медиана уровня ТБК-активных продуктов 
составила 11.94 мкмоль/л, интерквартильные и интерпроцентильные размахи [10.25; 15.04] [3.62; 16.48] мкмоль/л, что было статистически значимо выше по сравнению с группой соматически здоровых лиц. Эти данные еще раз подтверждают значение активации процессов перекисного окисления липидов в патогенезе ХОБЛ.

Известно, что каскад окислительно-восстановительных реакций напрямую зависит от воспалительной активности и запускается рядом воспалительных агентов. В своей работе мы также нашли подтверждение данной теории. Так, у пациентов с ХОБЛ нами была выявлена статистически значимая зависимость высокой силы между уровнем ТБК-активных продуктов и уровнем СРП $(\mathrm{r}=0.721 \mathrm{p}<0.001)$, отражающая усиление пероксидации липидов при увеличении системной воспалительной активации. Кроме того, была выявлена сильная прямая корреляционная взаимосвязь между уровнем ТБКактивных продуктов и уровнем плазменного фракталкина $(\mathrm{r}=0.894 \mathrm{p}<0.001)$. Эта взаимосвязь указывала, что именно возрастание уровня цитокинов-хемокинов, увеличивающее хемотаксис клеток воспаления, способствует инициализации и поддержанию оксидативного стресса, а именно процессов перекисного окисления липидов. Таким образом, можно сделать вывод, что у пациентов с ХОБЛ значимо увеличивается активность процессов перекисного окисления липидов, являясь плацдармом для системного поражения сосудистого русла.

Далее в своей работе мы оценили активность перекисного окисления белков по уровню карбонильных производных (КП). Уровень КП при ХОБЛ был статистически значимо выше, чем в группе соматически здоровых лиц. У пациентов с ХОБЛ медиана уровня КП составила 19.89 мкмоль/л, интерквартильные и интерпроцентильные размахи [17.25; 24.23] [7.76; 26.83] мкмоль/л. Эти данные указывают на большую активацию процессов перекисного окисления белковых молекул при ХОБЛ. На наш взгляд, это связано с большей выраженностью системного воспаления при ХОБЛ, что подтверждалось наличием в группе больных ХОБЛ статистически значимой зависимость средней силы между уровнем КП и уровнем СРП $(\mathrm{r}=0.615 \mathrm{p}<0.001)$, отражающей усиление пероксидации белков при увеличении системной воспалительной активации. Кроме того, была выявлена прямая корреляционная взаимосвязь средней силы между уровнем КП и уровнем плазменного фракталкина ( $\mathrm{r}=0.633$ $\mathrm{p}<0.001)$. Эта взаимосвязь указывала, что именно возрастание уровня цитокинов-хемокинов способствует увеличению пероксидации белковых молекул. Таким образом, у пациентов с
ХОБЛ была выявлена избыточная активация процессов перекисного окисления белков и обнаружена связь между воспалительной активностью и активацией перекисного окисления белков.

Далее в своей работе мы оценили выраженность антиоксидантной защиты по активности супероксиддисмутазы (СОД). У пациентов с ХОБЛ активность СОД составила $10,7[7,03 ; 11,86][5,57 ; 18,94]$ у.е./мл, что было статистически значимо $(\mathrm{p}<0.001)$ ниже по сравнению с группой соматически здоровых лиц. Снижение антиоксидантной защиты, выявленное у пациентов с ХОБЛ, по нашему мнению, связано с выраженностью системного воспаления, снижающего выработку антиоксидантов. У пациентов с ХОБЛ была выявлена статистически значимая обратная зависимость средней силы между значением активности СОД и уровнем СРП ( $\mathrm{r}=-0,67 \mathrm{p}<0.001)$, отражающая подавляющее влияние системного воспаления на активность антиоксидантной защиты.

Таким образом, ХОБЛ характеризуется статистически значимым снижением вазодилатирующей способности сосудистого эндотелия. Общим свойством микрососудистого эндотелия, характерным для ХОБЛ, является уменьшение продолжительности вазодилатации (декрементные типы), указывающее на развитие ЭД. У пациентов с ХОБЛ выявлено статистически значимое повышение продукции ЭТ-1 и НУПС, отражающее ухудшение состояния микрососудистого эндотелия. Исследование 4a/4b полиморфизма гена eNOS имеет важное значение в диагностике повреждения эндотелия при ХОБЛ. Генотип $4 \mathrm{a} / 4 \mathrm{~b}$ является фактором риска дисфункции эндотелия.

При ХОБЛ важное клинико-диагностическое значение имеет исследование иммунохимических биомаркеров воспаления. О системной воспалительной реакции при ХОБЛ свидетельствует гиперпродукция С-реактивного протеина и фракталкина.

У больных ХОБЛ установлено наличие окислительного стресса, опосредованного перекисной деструкцией как липидных, так и белковых молекул. Констатирована прямая корреляционная зависимость средней силы между уровнем плазменного эндотелина-1 и уровнем ТБК-активных продуктов, отражающая увеличение продукции вазоконстрикторов при увеличении уровня продуктов перекисного окисления липидов в группе больных ХОБЛ.

ХОБЛ - системное заболевание, характеризующееся вовлечением многих органов и тканей организма и комплексом расстройств различных систем гомеостаза. В нашей работе мы 
доказали поражение таких звеньев гомеостаза при ХОБЛ, как функциональное состояние микрососудистого эндотелия, воспалительный каскад, процессы перекисного окисления белковых и липидных структур, состояние антиоксидантной защиты, что закономерно может оказывать влияние как на течение заболевания, так и на его прогноз.

\section{ЛИТЕРАТУРА}

1. Глобальная стратегия диагностики, лечения и профилактики хронической обструктивной болезни легких (пересмотр 2011 г.) / Пер. с англ. под ред. А.С. Белевского. - М. : Российское респираторное общество, 2012. - 80 с., ил.

2. Дубинина E.E. Продукты метаболизма кислорода в функциональной активности клеток: (жизнь и смерть, созидание и разрушение). Физиологические и клинико-биохимические аспекты. - СПб. : Медицинская пресса, 2006. 397 c.

3. Новикова Н.Е., Кудряшева И.А., Ахминеева А.Х. Окислительный стресс при хронической обструктивной болезни легких // Астраханский медицинский журнал. - 2012. - Т. 7, № 3. С. 87-90.

4. Реброва О.Ю. Статистический анализ медицинских данных. Применение пакета прикладных программ STATISTICA. - M. : МедиаСфера, 2002. - 312 с.

5. Соодаева С.К. Окислительный стресс и антиоксидантная терапия при заболеваниях органов дыхания // Пульмонология. - 2006. - Т. 5, № 4. - С. 122-126.

6. Способ диагностики эндотелиальной дисфункции по типам реагирования микрососудистого эндотелия : пат. 2449282 Рос. Федерация, МПК G 01 N 33/483/ Л.П. Воронина, Е.А. Полунина, И.В. Нуржанова, О.С. Полунина, С.А. Голубкина. - № 2010132337 (045781) ; заявлено 2.08.10 ; опубл. 27.04.12., Бюл. № 12. - 4 с.

7. Способ оценки функционального состояния микрососудистого эндотелия у больных бронхиальной астмой : пат. 2436091 Рос. Федерация, МПК G 01 N 33/483 / И.В. Нуржанова, О.С. Полунина, Л.П. Воронина, Е.А. Полунина. № 2010124218 (034521) ; заявлено 11.06.10 ; опубл. 10.12.11., Бюл. № 34. - 3 с.

8. Уклистая Т.А., Гусейнов Г.Т., Галимзянов Х.М., Полунина О.С., Никифорова Н.В. Прогностические факторы хронической обструктивной болезни легких с частыми обострениями // Астраханский медицинский журнал. - 2012. - Т. 7, № 3. C. $114-117$.

9. Чучалин А.Г. Хроническая обструктивная болезнь легких и сопутствующие заболевания // Пульмонология. - 2008. - № 2. - С. 5-14.

10. Шаповалова Т.Г., Рябова А.Ю., Пластинина Е.С., Пономарева О.А., Шелобанова Н.В., Шашина М.М., Закирова В.Б. Хроническая обструктивная болезнь легких у пациентов кардиологического профиля: проблемы диагностики и лечения // Вестник современной клинической медицины. - 2016. - Т. 9, № 1. C. $79-83$.

11. Якушева Э.В., Уклистая Т.А., Полунина О.С., Воронина Л.П., Нуржанова И.В. Состояние микрокровотока у больных хронической обструктивной болезнью легких в зависимости от возраста и тяжести заболевания // Астраханский медицинский журнал. - 2011. - Т. 6, № 1. С. 132-134. 